\title{
Mechanistic Insights into Plant Chiral Growth
}

\author{
Masayoshi Nakamura ${ }^{1, *(1)}$ and Takashi Hashimoto ${ }^{2, *}$ \\ 1 Institute of Transformative Bio-Molecules (WPI-ITbM), Nagoya University, Chikusa, Nagoya 464-8601, Japan \\ 2 Division of Biological Sciences, Nara Institute of Science and Technology, 8916-5 Takayama, Ikoma, \\ Nara 630-0192, Japan \\ * Correspondence: mnakamu@itbm.nagoya-u.ac.jp (M.N.); hasimoto@bs.naist.jp (T.H.)
}

Received: 10 November 2020; Accepted: 10 December 2020; Published: 11 December 2020

\begin{abstract}
The latent left-right asymmetry (chirality) of vascular plants is best witnessed as a helical elongation of cylindrical organs in climbing plants. Interestingly, helical handedness is usually fixed in given species, suggesting genetic control of chirality. Arabidopsis thaliana, a small mustard plant, normally does not twist but can be mutated to exhibit helical growth in elongating organs. Genetic, molecular and cell biological analyses of these twisting mutants are providing mechanistic insights into the left-right handedness as well as how potential organ skewing is suppressed in most plants. Growth direction of elongating plant cells is determined by alignment of cellulose microfibrils in cell walls, which is guided by cortical microtubules localized just beneath the plasma membrane. Mutations in tubulins and regulators of microtubule assembly or organization give rise to helical arrangements of cortical microtubule arrays in Arabidopsis cells and cause helical growth of fixed handedness in axial organs such as roots and stems. Whether tubulins are assembled into a microtubule composed of straight or tilted protofilaments might determine straight or twisting growth. Mechanistic understanding of helical plant growth will provide a paradigm for connecting protein filament structure to cellular organization.
\end{abstract}

Keywords: helical growth; handedness; microtubule; tubulin; Arabidopsis thaliana

\section{Introduction}

Unlike animals, many multicellular plants do not exhibit apparent left-right asymmetry in shape and arrangement of organs and their composing cells. However, there are numerous examples in which chirality develops in particular cell types or specific tissues of certain plant species. Plants may be conceived to possess potential chirality, which is generally suppressed to attain straight growth and radially symmetric development. Isolation and subsequent analyses of helical growth mutants in normally non-helical plants have advanced our understanding of plant chirality from subcellular to organ scales. This review summarizes what is known from analyses of such helical growth mutants, and proposes possible molecular origins of chirality. Helical growth mutants may have mechanistic relevance to growth behavior of climbing plants.

The twining habitat and tendril movements have attracted botanists from the era of Darwin [1,2]. Climbing plants attach their aerial axial organs to a neighboring support in order to grow vertically and to collect more sunlight for efficient photosynthesis [3]. Twining plants generally show either left-handed or right-handed coils, and the handedness of twist is a fixed property in the species [4]. Morning glories twist in a right-handed orientation while hops and honeysuckles are left-handed. Within a single genus, both left and right-handed species may exist. For instance, there are three native species of Wisteria in the Japanese islands, where Wisteria brachybotrys shows a right-handed twist, whereas $W$. floribunda and W. japonica are left-handed [5]. In nature, right-handed tendrils are predominant. When 1485 twining plants were randomly sampled in 17 globally widespread locations, 92 percent of twining stems showed right-handed helices [6]. 
There are other forms or patterns of chirality in plant growth and development; oscillating movement of primary root apices and shoot apices in a circumnutating helix, clockwise or anti-clockwise arrangements of petals, twisted growth in leaves and seed pods, and spiral initiation patterns of leaf and flower primordia on the flank of a shoot apex [2,7-9]. In these cases, chirality handedness is often random or not fixed. Since underlying mechanisms are likely distinct, they are not reviewed here.

\section{Cellular Basis of Organ Twisting}

Twisting mutants of Arabidopsis thaliana, a tale cress plant with non-climbing habitat, provides mechanistic understanding of organ twisting. Twisting of axial organs, such as primary roots, hypocotyls, petioles, and stems, can be readily recognized by helical arrangements of epidermal cell files (Figures 1 and 2). For the entire organs to twist, however, internal cell layers need to change their cell shapes or growth patterns to coordinate organ growth and maintain organ integrity. Cell files of Arabidopsis hypocotyls and primary roots consist, from outer cell layers inward, of epidermis, cortex, endodermis, pericycle, and vascular cylinder (or stele, which contains several cell types). In these organs of twisting mutants, cells in the meristematic zone appear normal in size and shape while the axial organs begin to skew as the epidermal cells increase their longitudinal length [10,11]. The fact that cell division has completed in the hypocotyl (embryonic stem) during embryogenesis [12] is consistent with our interpretation that cell elongation (polar cell growth) underlies organ twisting. Sliding growth, i.e., slipping movement of one cell layer relative to its adjacent one, has not been observed in twisting roots [13]. Cell-cell adhesion is required to cause global organ torsion [14].

Microscopic observation of each cell layer in these twisting organs revealed that the angle between cell files and the axis of a twisted organ decreases from the periphery toward the organ center [13]. In accordance with predicted geometric constraints, epidermal cells elongate to attain a wild-type slender shape while internal cortex and endodermis cells swell radially [10]. An important question is whether the position-dependent deformation of cell shape is a cause or a consequence of organ twisting. The outermost epidermal cell layer mainly controls growth of the entire organ in shoots and roots [16,17]. Possibly, epidermal torsion causes longitudinal shrinkage and radial swelling in entire axial organs; internal cells may passively succumb to global deformation and adopt more isotropic cell shape. In addition to the mechanical interplay, the model must include hormonal signaling from epidermis to inner cells for coordinated growth control [16]. Less deformed innermost stele cells and the surrounding pericycle cells are much less deformed, in contrast to the expectations from the epidermis-leading model, in twisting mutants, suggesting a cell type-dependent control of cell shape [10].
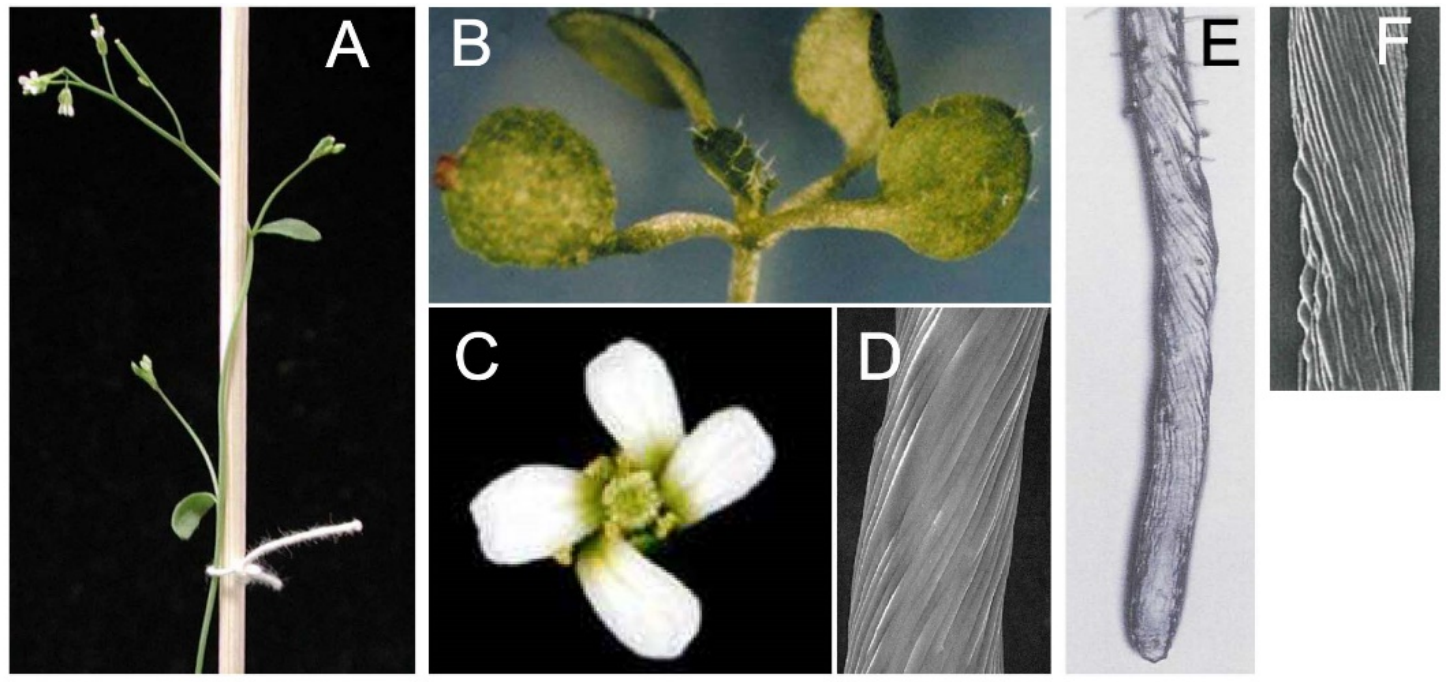

Figure 1. Cont. 

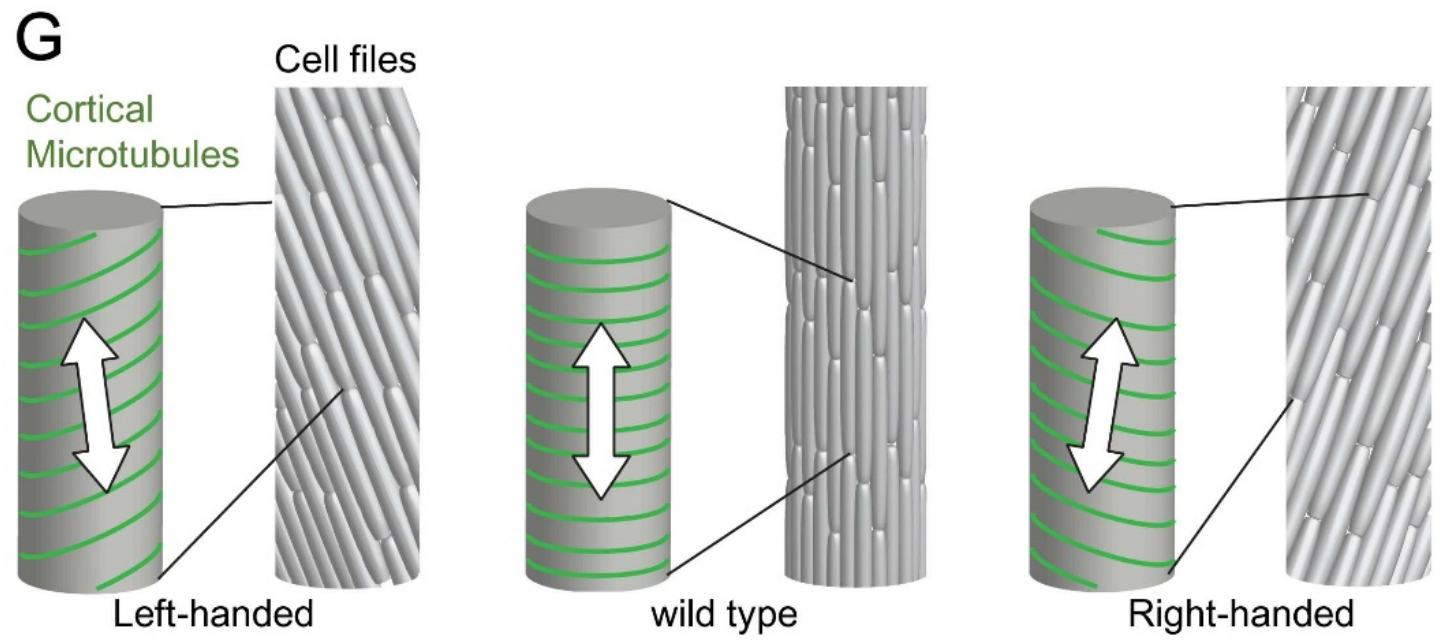

Figure 1. Organs, cell files, and organization models of cortical microtubules in twisting mutants and drug-treated wild-type plants. (A) Inflorescence stem of spiral1 spiral-like1 double mutant [15], which coils around a rod support. (B) Fan-like arrangement of cotyledons and the first two leaves of spiral2. (C) Anti-clockwise rotation of flower petals of sipral2. (D) Twisting etiolated hypocotyl of spiral1. (E) Wild-type primary root treated with a microtubule-depolymerizing drug ( $3 \mu \mathrm{M}$ propyzamide). (F) Wild-type light-grown hypocotyl treated with a microtubule-stabilizing drug $\left(0.4 \mathrm{mg} \mathrm{L}^{-1} \mathrm{taxol}\right)$. (G) Schematic representations of cortical microtubules (green lines) in an epidermal cell of rapidly elongating axial organs. Double-headed arrows indicate the direction of cell growth.
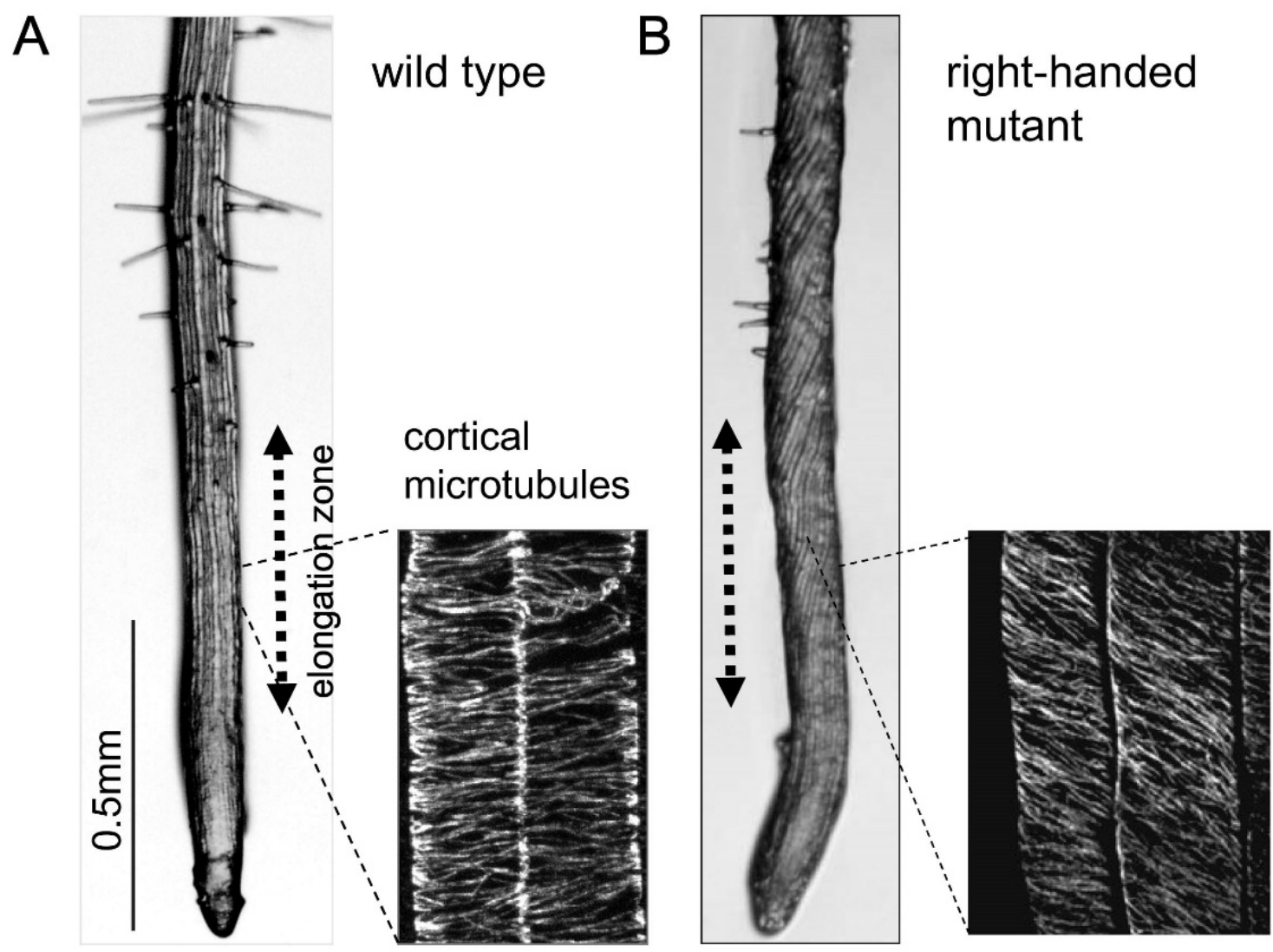

Figure 2. Primary roots of Arabidopsis seedlings. (A) wild type, (B) right-handed helical growth spiral1 mutant. Cortical microtubules at the early-mid elongation zone were immunostained with an $\alpha$-tubulin antibody. 
This general model of organ twisting implicates that, if the epidermal cells express a left-right handedness factor, the twisting axial organ shows a fixed handedness, while in the absence of such a factor, the organ would twist in random chirality. The latter example may be found in Arabidopsis twisting (usually dwarf) mutants with no fixed handedness [18]. In a multidrug resistance $\mathrm{ABC}$ transporter mutant and twisted dwarf 1, polar auxin transporters are mislocalized to abnormal subcellular locations and auxin signaling is spread into the elongation zone of a skewing primary root in a non-uniform manner [19], suggesting abnormal hormonal regulation in elongating tissues. Helical growth with random or non-fixed handedness is not further discussed here.

\section{Microtubule Defects Cause Helical Growth}

Dozens of twisting Arabidopsis helical growth mutants with fixed handedness were subjected to molecular genetic analyses, and were found to be caused by loss-of-function or gain-of-function mutations in microtubule-related genes. A majority of these mutants result from missense mutations in one of the several tubulin genes that are expressed in Arabidopsis vegetative tissues [20]. These mutant tubulins, together with wild-type tubulin isoforms, are assembled into microtubules, and cause dysfunctions of the poisoned polymer in a dominant-negative manner [11,21]. Other mutations include specific microtubule regulators that preferentially act on the plus end (SPIRAL1; [22,23]) or on the both ends (SPIRAL2; [24-28]), a component of the microtubule nucleating complex (SPIRAL3; [29]), and a tubulin kinase that converts $\alpha$-tubulins into an assembly-incompetent form [30,31]. Interestingly, right-handed helical mutants were more frequently isolated over left-handed mutants in these genetic screens, coincident with natural predominant occurrence of right-handed twisting plants [6]. In addition to the genetic evidence, application of low dosages of either microtubule-depolymerizing or-stabilizing drugs to the growth medium causes left-handed helical growth in normally non-twisting wild-type Arabidopsis seedlings [10,32]. These results indicate that proper regulation of microtubule organization is essential to sustain straight growth during cell elongation.

Polar or directional expansion of plant cells is generally directed by a network of cortical microtubules just beneath the cell membrane [33]. Cortical microtubules in the rapidly elongating cells, such as the root elongation zone and the etiolated hypocotyl, form bundled hoops and are roughly aligned in the direction perpendicular to the elongation axis. Cellulose synthase complexes travel along the microtubule rail in the plasma membrane [34] and spur out multiple cellulose polymers, then instantaneously assemble into crystalline microfibrils in the cell wall [35]. These load-bearing microfibrils, along with other types of cell wall polymers, are thought to restrict lateral expansion and to form a long cylindrical cell shape [36]. The anisotropic cell shape generates biased tension stress. Cortical microtubules somehow "sense" the maximal force direction and orient themselves parallel to the direction [37]. This proposed feedback mechanism would reinforce anisotropic expansion of plant cells.

The net transverse orientations of microtubule arrays in rapidly elongating wild-type cells are skewed to form right-handed helices in left-handed twisting mutants, and left-handed helices in right-handed mutants. A striking inverse correlation was observed between the root slanting angles and pitch angles of cortical microtubules, when 24 twisting tubulin mutants were analyzed [20]. Helical microtubule arrays begin to develop in the root epidermal cells in the early elongation zone, where root slanting is yet to be distinct, indicating that skewed microtubules orientation is the cause, rather than a consequence, of root twisting [11,20]. Helical microtubule arrays are also seen in an isolated single cell of a tubulin mutant [38]. Helical arrays are generally observed in other non-tubulin twisting mutants with fixed handedness $[10,11,21-25,29,30]$, but not in twisting mutants with random handedness ([19] and our unpublished results).

What microtubule attributes are responsible for generation of helical arrays? In the interphase plant cells, new microtubules are mostly formed from the nucleating complex dispersed along the preexisting microtubules at an angle of about 40 degrees [39], are released from the initial nucleation sites by katanin [40], and migrate at the cell cortex by a polymerization-biased hybrid 
treadmilling mechanism [41], while associating with the inner quasi-2D surface of the plasma membrane. Freely migrating microtubules are also generated by severing of overriding microtubules at the cortical microtubule crossover sites by katanin [42]. Abundant migrating cortical microtubules often encounter with one another; when the growing plus end of one microtubule collide with the lateral wall of an obstructing microtubule, collisions at angles of less than 40 degrees generally result in bundling of two microtubules, while collisions at larger encounter angles typically induce catastrophe at the growing plus end or enable the approaching microtubule to crossover the blocking microtubule [43]. These dynamic behaviors are predicted to prune discordant microtubules and arrange whole microtubule populations into distinct arrays [44]. By surveying the spectrum of responsive genes causing helical growth, it is difficult to pinpoint any particular microtubule events to be responsible for helical array formation. Although growth and shrinkage parameters of cortical microtubules of twisting tubulin mutants are altered from those of wild type, any apparent tendency is not observed in microtubule dynamic instability that would correlate with helical handedness [21].

Although microtubule-based helical growth in plants is generally well established, there are notable cases in which observed helical growth patterns of fixed handedness appear to be independent of microtubule orientation or have yet to be linked to microtubules. An Arabidopsis mutant defective in an uncharacterized glycoprotein anchored to the plasma membrane (and partly localized to the cell wall) exhibits left-handed helical growth in roots and etiolated hypocotyls [45]. Radiating cuticular nanoridges in conically shaped adaxial epidermal cells of the petal blade twist in a left-handed helix in an Arabidopsis mutant defective in rhamnose-containing cell wall polymers [46]. In these cases, some polymers in the cell wall might have innately handed chirality that manifests as helical cell expansion under certain conditions.

\section{Possible Origin of Microtubule Chirality}

Polar biopolymer may be helically arranged and as such may innately possess a fundamental chirality on its own. Actin, for example, is invariably assembled to a right-handed helical polymer. Chirality can emerge from handed cytoskeletons; Class I myosin motors anchored on a membrane surface walk along the helical actin pitch, and rotate actin filaments in leftward (counterclockwise) circles [47]. The right-handed actin helix can be "read" by Class V myosin as a left-handed spiral movement of the motor around the filament [48].

Although the microtubule cytoskeleton is typically depicted as a non-twisting polymer composed of 13 straight protofilaments in biology textbooks, it can also take helical configurations. When tubulin monomers were purified from bovine brain and were spontaneously assembled in vitro, microtubules ranging from 9 to 16 protofilaments were formed, with 14-protofilament microtubules being predominant [49]. Protofilaments in the 13-protofilament microtubules align parallel to the long axis of microtubules and serve as liner trails for motor-driven cellular cargos. However, in non-13-protofilament microtubules, protofilaments rotate around the microtubule's long axis to maintain the lattice integrity, giving rise to either a right-handed or left-handed protofilament twist (called supertwist) (Figure 3) [50,51]. Chirality and degree of the supertwist depend on the protofilament number and the monomer pitch per helical turn. Association of two microtubules into a bundle in either a parallel or anti-parallel fashion, which is a typical feature of plant cortical arrays [52], preserves the original chirality of a handed microtubule [53].

Do supertwisted microtubules occur in living cells? Although canonical 13-protofilament microtubules predominate in nature, including plants [21,54], there are several reports that microtubules with divergent protofilament numbers have been observed in certain cell types in particular species [55]. Ventral cord neurons of the nematode C. elegans, for instance, are well known to contain uniform 11-protofilament microtubules [56,57]. Thus, microtubules have an intrinsic flexibility to accommodate divergent numbers of protofilaments, but eukaryotic cells have evolved to specify the number as 13 in order to build straight-protofilament microtubules. 
A
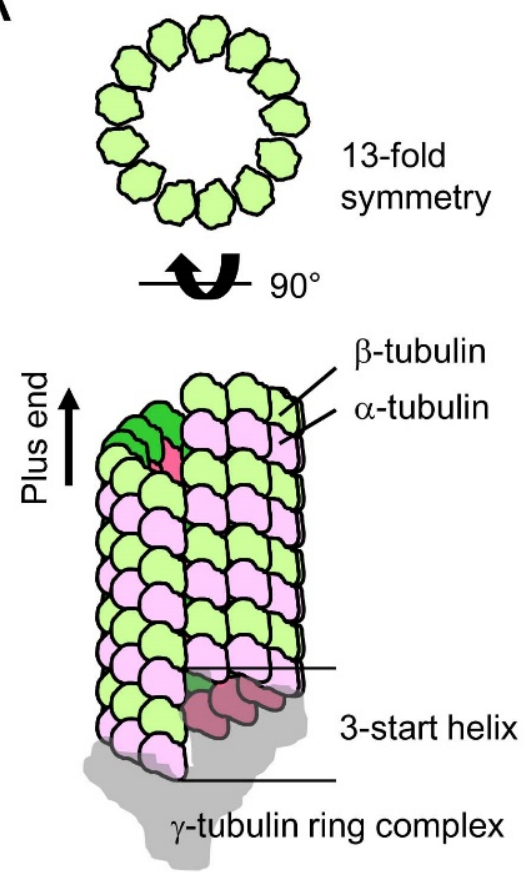

B

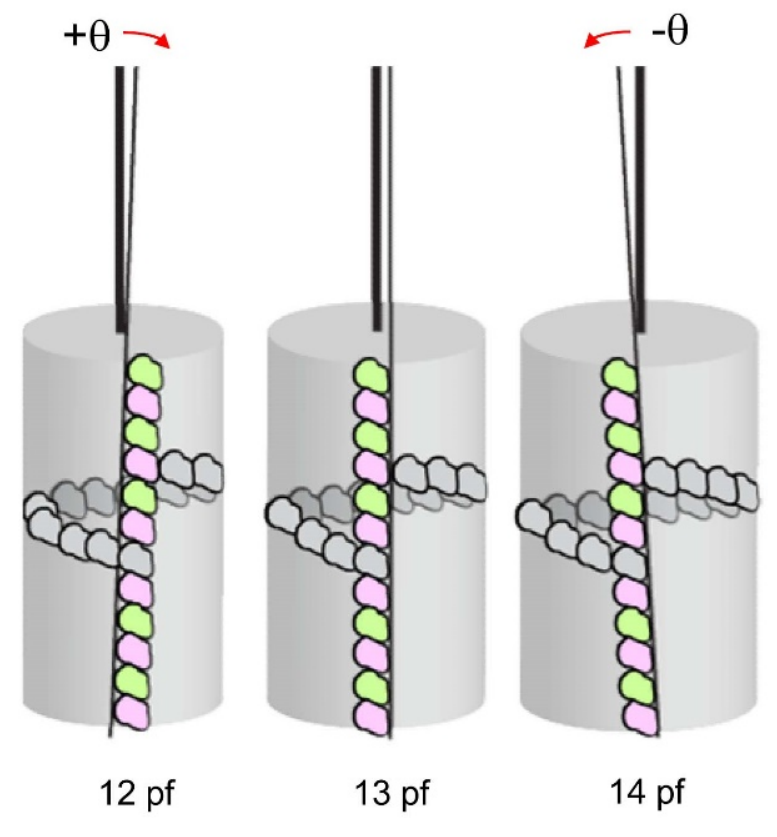

Figure 3. Microtubule structures. (A) Straight microtubule with 13 protofilaments nucleate from a $\gamma$-tubulin ring complex and grows toward the plus end with dynamic instability. (B) Protofilament arrangements in microtubules with 12, 13, and 14 protofilament (pf) numbers with a 3-start helical path. The lattice of 12-protofilament microtubules twists (supertwists) to the right $(+\theta)$ while the 14-protofilament lattice skews to the opposite direction $(-\theta)$, to accommodate a geometrical mismatch in the contacts between tubulins.

What determines the predominance of 13-protofilament microtubules in vivo, in contrast to the variabilities observed in vitro? The $\gamma$-tubulin-containing ring complex templates nucleation of a 13-protofilament microtubule, by arranging $13 \gamma$-tubulins in a washer-like shape that matches the minus-end geometry of a nascent microtubule (Figure 3) [58]. An Arabidopsis mutant which has a defect in a component of the ring complex shows strong right-handed helical growth phenotypes in elongating tissues [29]. Even after nucleating as a 13-protofilament microtubule, dynamic assembly and disassembly at the plus end may alter the protofilament number over time [59]. Some microtubule-associating proteins (MAPs) act as proof-reading factors and preferentially stabilize the 13-protofilament configuration; End-binding protein 1 (EB1) binds at the vertex of four tubulin dimers of two neighboring protofilaments at the growing plus end $[60,61]$ whereas a neuronal MAP, doublecortin, shares this binding site at the microtubule lattice [62]. Among dozens of various plant MAPs [63], only a small subset of them give chiral twisting phenotypes when mutated. Dynamic plus-end accumulation of SPIRAL1 [23] may have potential implications for its putative proof-reading activity. In addition to these regulations that favor abundance of 13-protofilament microtubules, tubulin isoforms are found to strongly affect the protofilament number in vitro. One purified human $\beta$-tubulin isoform assembles into a microtubule population of primarily 13 protofilaments, whereas another $\beta$-tubulin isoform gives predominantly 14-protofilament microtubules [64]. Therefore, small differences in the amino acid sequence of tubulins have the potential to produce non-13-protofilament microtubules, and may underlie the molecular mechanisms for twisting tubulin mutants in Arabidopsis. Electron microscopic analysis of less than a dozen cortical microtubules in tubulin mutants failed to detect deviation from 13 protofilaments [21], indicating that larger scale analysis needs to be done to identify a small fraction of chirality determinant microtubules in a whole population. 


\section{Conclusions and Outlook}

In this review, we propose that non-13-protofilament microtubules produce helical cortical arrays with defined handedness and chiral skewing of elongating axial organs in plants. How might the putative occurrence of non-13-protofilament microtubules develop into a mesoscale helical array? Stable association of cortical microtubules to the cytoplasmic surface of plasma membrane is arguably important to generate directional torque from actively migrating single microtubules and positionally more stable bundled microtubules. Computer simulations of cortical array ordering need to incorporate a realistic 3D cell model and all critical parameters in microtubule dynamics and the deterministic collisions (e.g., [44]), and may be applied to the helical arrays. In vitro experimental setups that recapture $2 \mathrm{D}$ or even $3 \mathrm{D}$ dynamic nematics of microtubule arrays will become highly promising approaches to decipher molecular interactions during emergence of larger-scale microtubule assemblies $[65,66]$. Principles governing hierarchical assemblies of mesoscale helical structures may even be learned from self-organization patterns of synthetic polymers $[67,68]$.

Chiral twisting of prokaryotic cytoskeletal filaments and resultant handed twisting in cell body of elongating bacteria would provide functional and mechanistic clues to helical growth of cylindrical plant cells. In the rod-shaped bacterium Escherichia coli, left-handed chirality of the MreB cytoskeleton (a bacterial F-actin-like polymer) guides local insertion of wall material into the peptidoglycan network, and causes cells to twist in a left-handed helix during elongation growth [69]. Molecular dynamics simulations for MreB in Caulobacter crescentus, another rod-shaped bacterium, suggest MreB double protofilaments can exhibit left-handed twisting and induce a stable membrane curvature when bound to the membrane [70]. Chiral arrangements of polar cytoskeletons underneath the cell-enclosing membrane may provide a common paradigm for helical growth in cylindrical plant cells and rod-shaped bacteria.

Evolutionary pressures and biological advantages of 13-protofilament microtubules in most eukaryotic cells are elusive [55]. In land plants, microtubule-driven growth axis control, by way of cellulose microfibril deposition, is a key feature for sustained straight growth in rapidly elongating cells. For the cortical microtubule arrays to be oriented transversely relative to the growth axis, plant microtubules should not manifest an asymmetric growth vector when migrating and self-organizing on the plasma membrane. In this process, potential helical asymmetry of microtubules needs to be actively suppressed, probably by inhibiting formation of non-13-protofilament microtubules. This suppression of chirality development may be relieved or partially lost in tendrils to assist the climbing habitat of twining plants. Straight axial growth in plants can only be attained by eliminating potential chirality factors.

Author Contributions: All authors designed and wrote the manuscript, and prepared the figures. All authors have read and agreed to the published version of the manuscript.

Funding: This work was supported by the Human Frontier Science Program to M.N., Grants-in-Aid for Scientific Research (18KK0195) to M.N. and T.H., (20H03276) to H.T. ITbM is supported by World Premier International Research Initiative (WPI), Japan.

Conflicts of Interest: The authors declare no conflict of interest.

\section{References}

1. Darwin, C. On the movements and habits of climbing plants. Bot. J. Linn. Soc. 1865, 9, 1-118. [CrossRef]

2. Darwin, C. The Power of Movement in Plants; John Murray: London, UK, 2017.

3. Gianoli, E. The behavioural ecology of climbing plants. AoB Plants 2015, 7, plv013. [CrossRef]

4. Isnard, S.; Silk, W.K. Moving with climbing plants from Charles Darwin's time into the 21st century. Am. J. Bot. 2009, 96, 1205-1221. [CrossRef] [PubMed]

5. Compton, J.A.; Lack, H.W. The discovery, naming and typification of Wisteria floribunda and W. brachybotrys (Fabaveae) with notes on associated names. Willdenowia 2012, 42, 219-240. [CrossRef]

6. Edwards, W.; Moles, A.T.; Franks, P. The global trend in plant twining direction. Glob. Ecol. Biogeogr. 2007, 16, 795-800. [CrossRef] 
7. Stolarz, M. Circumnutation as a visible plant action and reaction. Plant Signal. Behav. 2009, 4, 380-387. [CrossRef]

8. Hashimoto, T. Molecular genetic analysis of left-right handedness in plants. Philos. Trans. R. Soc. Biol. Sci. 2002, 357, 799-808. [CrossRef]

9. Smyth, D.R. Helical growth in plant organs: Mechanisms and significance. Development 2016, 143, $3272-3282$. [CrossRef]

10. Furutani, I.; Watanabe, Y.; Prieto, R.; Masukawa, M.; Suzuki, K.; Naoi, S.; Thitamadee, T.; Shikanai, T. The SPIRAL genes are required for directional control of cell elongation in Arabidopsis thaliana. Development 2000, 127, 4443-4453. [PubMed]

11. Thitamadee, S.; Tuchihara, K.; Hashimoto, T. Microtubule basis for left-handed helical growth in Arabidopsis. Nature 2002, 417, 193-196. [CrossRef]

12. Gendreau, E.; Traas, J.; Desnos, T.; Grandjean, O.; Caboche, M.; Hofte, H. Cellular basis of hypocotyl growth in Arabidopsis thaliana. Plant Physiol. 1997, 114, 295-305. [CrossRef] [PubMed]

13. Weizbauer, R.; Peters, W.S.; Schulz, B. Geometric constraints and the anatomical interpretation of twisted plant organ phenotypes. Front. Plant Sci. 2011, 2, 62. [CrossRef] [PubMed]

14. Verger, S.; Liu, M.; Hamant, O. Mechanical conflicts in twisting growth revealed by cell-cell adhesion defects. Front. Plant Sci. 2019, 10, 173. [CrossRef] [PubMed]

15. Nakajima, K.; Kawamura, T.; Hashimoto, T. Role of the SPIRAL gene family in anisotropic growth of Arabidopsis thaliana. Plant Cell Physiol. 2006, 47, 513-522. [CrossRef] [PubMed]

16. Savalde-Goldstein, S.; Chory, J. Growth cooridination and the shoot epidermis. Curr. Opin. Plant Biol. 2008, 11, 42-48. [CrossRef]

17. Vaseva, I.I.; Qudeimat, E.; Potuschak, T.; Du, Y.; Genschik, P.; Vandenbussche, F.; van der Straeten, D. The plant hormone ethylene restricts Arabidopsis growth via the epidermis. Proc. Natl. Acad. Sci. USA 2018, 115, E4130-E4139. [CrossRef]

18. Ishida, T.; Thitamadee, S.; Hashimoto, T. Twisted growth and organization of cortical microtubules. J. Plant Res. 2007, 120, 61-70. [CrossRef]

19. Wu, G.; Otegui, M.S.; Spalding, E.P. The ER-localized TWD1 immunophilin is necessary for localization of multidrug resistance-like proteins required for polar auxin transport in Arabidopsis roots. Plant Cell 2010, 22, 3295-3304. [CrossRef]

20. Hashimoto, T. Dissecting the cellular functions of plant microtubules using mutant tubulins. Cytoskeleton 2013, 70, 191-200. [CrossRef]

21. Ishida, T.; Kaneko, Y.; Iwano, M.; Hashimoto, T. Helical microtubule arrays in a collection of tubulin mutants of Arabidopsis thaliana. Proc. Natl. Acad. Sci. USA 2007, 104, 8544-8549. [CrossRef]

22. Nakajima, K.; Furutani, I.; Tachimoto, H.; Matsubara, K.; Hashimoto, T. SPIRAL1 encodes a novel plant-specific microtubule-localized protein required for directional cell control of rapidly expanding Arabidopsis cells. Plant Cell 2004, 16, 1178-1190. [CrossRef] [PubMed]

23. Sedbrook, J.C.; Ehrhardt, D.W.; Fisher, S.E.; Scheible, W.R.; Somerville, C.R. The Arabidopsis SKU6/SPIRAL1 gene encodes a plus end-localized microtubule-interacting protein involved in directional cell expansion. Plant Cell 2004, 16, 1506-1520. [CrossRef] [PubMed]

24. Shoji, T.; Narita, N.N.; Hayashi, K.; Asada, J.; Hamada, T.; Sonobe, S.; Nakajima, K.; Hashimoto, T. Plant-specific microtubule-associated protein SPIRAL2 is required for anisotropic growth in Arabidopsis. Plant Physiol. 2004, 136, 3933-3944. [CrossRef] [PubMed]

25. Bushmann, H.; Fabri, C.O.; Hauptmann, M.; Hutzler, P.; Laux, T.; Lloyd, C.W.; Schäffner, A.R. Helical growth of the Arabidopsis mutant tortifolia1 reveals a plant-specific microtubule-associated protein. Curr. Biol. 2004, 14, 1515-1521. [CrossRef] [PubMed]

26. Yao, M.; Wakamatsu, Y.; Itoh, T.J.; Shoji, T.; Hashimoto, T. Arabidopsis SPIRAL2 promotes uninterrupted microtubule growth by suppressing the pause state of microtubule dynamics. J. Cell Sci. 2008, 121, 2372-2381. [CrossRef] [PubMed]

27. Nakamura, M.; Lideboom, J.J.; Saltini, M.; Mulder, B.M.; Ehrhardt, D.W. SPR2 protects minus ends to promote severing and reorientation of plant cortical microtubule arrays. J. Cell Biol. 2018, 217, 915-927. [CrossRef]

28. Fan, Y.; Burkart, G.M.; Dixit, R. The Arabidopsis SPIRAL2 protein targets and stabilizes microtubule minus ends. Curr. Biol. 2018, 28, 987-994. [CrossRef] 
29. Nakamura, M.; Hashimoto, T. A mutation in the Arabidopsis $\gamma$-tubulin-containing complex subunit causes helical growth and abnormal microtubule branching. J. Cell Sci. 2009, 122, 2208-2217. [CrossRef]

30. Naoi, K.; Hashimoto, T. A semi-dominant mutation in an Arabidopsis mitogen-activated protein kinase phosphatase-like gene compromises cortical microtubule organization. Plant Cell 2004, 16, 1841-1853. [CrossRef]

31. Fujita, S.; Pytela, J.; Hotta, T.; Kato, T.; Hamada, T.; Akamatsu, R.; Ishida, Y.; Kutsuna, N.; Hasezawa, S.; Nomura, Y.; et al. An atypical tubulin kinase mediates stress-induced microtubule depolymerization in Arabidopsis. Curr. Biol. 2013, 23, 1969-1978. [CrossRef]

32. Nakamura, M.; Naoi, K.; Shoji, T.; Hashimoto, T. Low concentrations of propyzamide and oryzalin alter microtubule dynamics in Arabidopsis epidermal cells. Plant Cell Physiol. 2004, 45, 1330-1334. [CrossRef] [PubMed]

33. Baskin, T.I. On the alignment of cellulose microfibrils by cortical microtubules: A review and a model. Protoplasma 2001, 215, 150-171. [CrossRef] [PubMed]

34. Paredez, A.R.; Somerville, C.R.; Ehrhardt, D.W. Visualization of cellulose synthase demonstrates functional association with microtubules. Science 2006, 312, 1491-1495. [CrossRef] [PubMed]

35. Purushotham, P.; Ho, R.; Zimmer, J. Architecture of a catalytically active homotrimeric plant cellulose synthase complex. Science 2020, 369, 1089-1094. [CrossRef]

36. Green, P.B. Mechanism for plant cellular morphogenesis. Science 1962, 138, 1404-1405. [CrossRef]

37. Hamant, O.; Inoue, D.; Bouchez, D.; Dumais, J.; Mjolsness, E. Are microtubule tension sensors? Nat. Commun. 2019, 10, 2360. [CrossRef]

38. Buschmann, H.; Hauptmann, M.; Niessing, D.; Lloyd, C.W.; Schäffner, A.R. Helical growth of the Arabidopsis mutant tortifolia 2 does not depend on cell division patterns but involves handed twisting of isolated cells. Plant Cell 2009, 21, 2090-2106. [CrossRef]

39. Murata, T.; Sonobe, S.; Baskin, T.I.; Hyodo, S.; Hasezawa, S.; Nagata, T.; Horio, T.; Hasebe, M. Microtubule-dependent microtubule nucleation based on recruitment of $\gamma$-tubulin in higher plants. Nat. Cell Biol. 2005, 7, 961-968. [CrossRef]

40. Nakamura, M.; Ehrhardt, D.; Hashimoto, T. Microtubule and katanin dependent dynamics of microtubule nucleation complexes in the Arabidopsis cortical array. Nat. Cell Biol. 2010, 12, 1064-1070. [CrossRef]

41. Shaw, S.; Kamyar, R.; Ehrhardt, D. Sustained microtubule treadmilling in Arabidopsis cortical arrays. Science 2003, 300, 1715-1718. [CrossRef]

42. Lindeboom, J.J.; Nakamura, M.; Hibbel, A.; Shundyak, K.; Guierrez, R.; Ketelaar, T.; Emons, A.M.C.; Mulder, B.M.; Kirik, V.; Ehrhardt, D.W. A mechanism for reorientation of cortical microtubule arrays driven by microtubule severing. Science 2013, 342, 1245533. [CrossRef] [PubMed]

43. Dixit, R.; Cyr, R. Encounters between dynamic cortical microtubules promote ordering of the cortical array through angle-dependent modifications of microtubule behavior. Plant Cell 2004, 16, 274-284. [CrossRef] [PubMed]

44. Tindermans, S.H.; Deinum, E.E.; Lindeboom, J.J.; Mulder, B.M. Efficient event-driven simulations shed new light on microtubule organization in the plant cortical array. Front. Phys. 2014, 2, 19.

45. Sedbrook, J.C.; Carroll, K.L.; Hung, K.F.; Masson, P.H.; Somerville, C.R. The Arabidopsis SKU5 gene encodes an extracellular glycosyl phosphatidylinositol-anchored glycoprotein involved in directional root growth. Plant Cell 2002, 14, 1635-1648. [CrossRef] [PubMed]

46. Saffer, A.M.; Carpita, N.C.; Irish, V.F. Rhamnose-containing cell wall polymers suppress helical plant growth independently of microtubule orientation. Curr. Biol. 2017, 27, 2248-2259. [CrossRef] [PubMed]

47. Pyrpassopoulos, S.; Feeser, E.A.; Mazerik, J.N.; Tyska, M.J.; Ostap, E.M. Membrane-bound myo1c powers asymmetric motility of actin filaments. Curr. Biol. 2012, 22, 1688-1692. [CrossRef]

48. Ali, M.Y.; Uemura, S.; Adachi, K.; Itoh, H.; Kionoshita, K.; Ishiwata, S. Myosin V is a left-handed spiral motor on the right-handed actin helix. Nat. Struct. Biol. 2002, 9, 464-467. [CrossRef]

49. Pierson, G.B.; Burton, P.R.; Himes, R.H. Alterations in number of protofilaments in microtubules assembled in vitro. J. Cell Biol. 1978, 76, 223-228. [CrossRef]

50. Chretien, D.; Wade, R.H. New data on the microtubule surface lattice. Biol. Cell 1991, 71, 161-174. [CrossRef]

51. Sui, H.; Downing, K.H. Structural basis of interprotofilament interaction and lateral deformation of microtubules. Structure 2010, 18, 1022-1031. [CrossRef]

52. Yagi, N.; Matsunaga, S.; Hashimoto, T. Insights into cortical microtubule nucleation and dynamics in Arabidopsis leaf cells. J. Cell Sci. 2018, 131, jcs203778. [CrossRef] [PubMed] 
53. Hashimoto, T. Microtubule and cell shape determination. In The Plant Cytoskeleton; Liu, B., Ed.; Springer: New York, NY, USA, 2011; Chapter 11; pp. 245-257.

54. Ledbetter, M.C.; Porter, K.R. Morphology of microtubules of plant cells. Science 1964, 144, 872-874. [CrossRef] [PubMed]

55. Chaaban, S.; Brouhard, G.J. A microtubule bestiary: Structural diversity in tubulin polymers. Mol. Biol. Cell 2017, 28, 2924-2931. [CrossRef] [PubMed]

56. Chalfie, M.; Thomson, J.N. Structural and functional diversity in the neuronal microtubules of Caenorhabditis elegans. J. Cell Biol. 1982, 93, 15-23. [CrossRef] [PubMed]

57. Chaaban, S.; Jariwala, S.; Hsu, C.T.; Redemann, S.; Kollman, J.M.; Müller-Reichert, T.; Sept, D.; Bui, K.H.; Brouhard, G.J. The structure and dynamics of C. elegans tubulin reveals the mechanistic basis of microtubule growth. Dev. Cell 2018, 47, 191-204. [CrossRef] [PubMed]

58. Liu, P.; Wurz, M.; Zupa, E.; Pfeffer, S.; Schiebel, E. Microtubule nucleation: The waltz between $\gamma$-tubulin ring complex and associated proteins. Curr. Opin. Cell Biol. 2020, 68, 124-131. [CrossRef]

59. Chretien, D.; Fuller, S.D. Microtubule switch occasionally into unfavorable configurations during elongation. J. Mol. Biol. 2000, 298, 663-676. [CrossRef]

60. Vitre, B.; Coquelle, F.M.; Heichette, C.; Garnier, C.; Chretien, D.; Arnal, I. EB1 regulates microtubule dynamics and tubulin sheet closure in vitro. Nat. Cell Biol. 2008, 10, 415-421. [CrossRef]

61. Maurer, S.P.; Fourniol, F.J.; Bohner, G.; Moores, C.A.; Surrey, T. EBs recognize a nucleotide-dependent structural cap at growing microtubule ends. Cell 2012, 149, 371-382. [CrossRef]

62. Moores, C.A.; Perderiset, M.; Francis, F.; Chelly, J.; Houdusse, A.; Milligan, R.A. Mechanism of microtubule stabilization by doublecortin. Mol. Cell 2004, 14, 833-839. [CrossRef]

63. Hamada, T. Microtubule organization and microtubule-associated proteins in plants. In International Review of Cell and Molecular Biology; Academic Press: London, UK, 2014; Volume 312, pp. 1-52.

64. Ti, S.C.; Alushin, G.M.; Kapoor, T.M. Human $\beta$-tubulin isotypes can regulate microtubule protofilament number and stability. Dev. Cell 2018, 47, 175-190. [CrossRef] [PubMed]

65. Sumino, Y.; Nagai, K.H.; Shitaka, Y.; Tanaka, D.; Yoshikawa, K.; Chaté, H.; Oiwa, K. Large-scale vortex lattice emerging from collectively moving microtubules. Nature 2012, 483, 448-452. [CrossRef] [PubMed]

66. Duclos, G.; Adkins, R.; Banerjee, D.; Peterson, M.S.E.; Varghese, M.; Kolvin, I.; Baskaran, A.; Pelcovits, R.A.; Powers, T.R.; Baskaran, A.; et al. Topological structure and dynamics of three-dimensional active nematics. Science 2020, 357, 1120-1124. [CrossRef] [PubMed]

67. Pokroy, B.; Kang, S.H.; Mahadevan, L.; Aizenberg, J. Self-organization of a mesoscale bristle into ordered, hierarchical helical assemblies. Science 2009, 323, 237-240. [CrossRef]

68. Shen, H.; Fallas, J.A.; Lynch, E.; Sheffler, W.; Parry, B.; Jannetty, N.; Decarreau, J.; Wagenbach, M.; Vicente, J.J.; Chen, J.; et al. De novo design of self-assembling helical protein filaments. Science 2018, 362, 705-709. [CrossRef]

69. Wang, S.; Furchtgott, L.; Huang, K.C.; Shaevitz, J.W. Helical insertion of peptidoglycan produces chiral ordering of the bacterial cell wall. Proc. Natl. Acad. Sci. USA 2012, 109, 3611. [CrossRef]

70. Shi, H.; Quint, D.A.; Grason, G.M.; Gopinathan, A.; Huang, K.C. Chiral twisting in a bacterial cytoskeletal polymer affects filament size and orientation. Nat. Commun. 2020, 11, 1408. [CrossRef]

Publisher's Note: MDPI stays neutral with regard to jurisdictional claims in published maps and institutional affiliations.

(C) 2020 by the authors. Licensee MDPI, Basel, Switzerland. This article is an open access article distributed under the terms and conditions of the Creative Commons Attribution (CC BY) license (http://creativecommons.org/licenses/by/4.0/). 